\title{
Association between renin-angiotensin-aldosterone system inhibitor treatment, neutrophil-lymphocyte ratio, D-Dimer and clinical severity of COVID-19 in hospitalized patients: a multicenter, observational study
}

\author{
Selcuk Gormez ${ }^{1} \cdot$ Erkan Ekicibasi $^{2} \cdot$ Aleks Degirmencioglu $^{3} \cdot$ Ashok Paudel $^{4} \cdot$ Refik Erdim $^{5} \cdot$ Hilal Kurtoglu Gumusel $^{6}$. \\ Elif Eroglu $^{7} \cdot$ Ibrahim Halil Tanboga $^{8,9,10} \cdot$ Sinan Dagdelen ${ }^{7} \cdot$ Nevin Sariguzel $^{11} \cdot$ Ceyda Erel Kirisoglu $^{12}$. \\ Burak Pamukcu iD ${ }^{13}$
}

Received: 12 June 2020 / Revised: 10 August 2020 / Accepted: 14 August 2020 / Published online: 24 August 2020

(c) The Author(s), under exclusive licence to Springer Nature Limited 2020

\begin{abstract}
The aim of this study was to investigate the possible relationship between worse clinical outcomes and the use of angiotensinconverting enzyme inhibitors (ACEIs) or angiotensin receptor blockers (ARBs) in hospitalized COVID-19 patients. A total of 247 adult patients (154 males, 93 females; mean age: 51.3 \pm 14.2 years) hospitalized for COVID-19 as confirmed by polymerase chain reaction (PCR) were retrospectively reviewed. Demographic and clinical characteristics and laboratory parameters were analyzed using various statistical modeling. Primary outcomes were defined as the need for intensive care unit (ICU), mechanical ventilation, or occurrence of death. Of the patients, 48 were treated in the ICU with a high flow oxygen/noninvasive mechanical ventilation (NIMV, $n=12)$ or mechanical ventilation $(n=36)$. Median length of ICU stay was 13 (range, 7-18) days. Mortality was seen in four of the ICU patients. Other patients were followed in the COVID-19 services for a median of 7 days. There was no significant correlation between the primary outcomes and use of ACEIs/ARBs (frequentist $\mathrm{OR}=0.82,95 \%$ confidence interval $(\mathrm{CI}) 0.29-2.34, p=0.715$ and Bayesian posterior median $\mathrm{OR}=0.80,95 \%$ CI 0.31-2.02) and presence of hypertension (frequentist $\mathrm{OR}=1.23,95 \% \mathrm{CI} 0.52-2.92, p=0.631$ and Bayesian posterior median $\mathrm{OR}=1.25,95 \%$ CI 0.58-2.60). Neutrophil-to-lymphocyte ratio (NLR) and D-dimer levels were strongly associated with primary outcomes. In conclusion, the presence of hypertension and use of ACEIs/ARBs were not significantly associated with poor primary clinical outcomes; however, NLR and D-dimer levels were strong predictors of clinical worsening.
\end{abstract}

Burak Pamukcu

burak.pamukcu@acibadem.edu.tr

1 Department of Cardiology, Faculty of Medicine, Acibadem Kadikoy Hospital, Acibadem Mehmet Ali Aydinlar University, Istanbul, Turkey

2 Department of Cardiology, Vocational School of Health Services, Acibadem Altunizade Hospital, Acibadem Mehmet Ali Aydinlar University, Istanbul, Turkey

3 Department of Cardiology, Faculty of Medicine, Acibadem Maslak Hospital, Acibadem Mehmet Ali Aydinlar University, Istanbul, Turkey

4 Department of Cardiology, Acibadem Altunizade Hospital, Istanbul, Turkey

5 Department of Cardiology, Vocational School of Health Services, Acibadem Kadikoy Hospital, Acibadem Mehmet Ali Aydinlar University, Istanbul, Turkey

6 Department of Cardiology, Acibadem Kadikoy Hospital, Istanbul, Turkey
7 Department of Cardiology, Faculty of Medicine, Acibadem Altunizade Hospital, Acibadem Mehmet Ali Aydinlar University, Istanbul, Turkey

8 Department of Cardiology, Nisantasi University, Istanbul, Turkey

9 Department of Biostatistics, Medical School, Ataturk University, Erzurum, Turkey

10 Department of Cardiology, Hisar Intercontinental Hospital, Istanbul, Turkey

11 Department of Infectious Diseases, Acibadem Kadikoy \& Kozyatagi Hospitals, Istanbul, Turkey

12 Department of Chest Diseases and Tuberculosis, Faculty of Medicine, Acibadem Kozyatagi Hospital, Acibadem Mehmet Ali Aydinlar University, Istanbul, Turkey

13 Department of First and Emergency Aid, Department of Cardiology, Acibadem Kozyatagi Hospital, Vocational School of Health Services, Acibadem Mehmet Ali Aydinlar University, Istanbul, Turkey 


\section{Introduction}

In December 2019, a cluster of pneumonia cases emerged in Wuhan, the capital city of Hubei province of China [1]. As the number of cases increased rapidly throughout the country, resulting in an epidemic, China reported a cluster of cases with new infectious respiratory disease with unknown etiology originating from Wuhan to the World Health Organization (WHO) [2]. On January 7th, 2020, a Chinese scientist identified the pathogen as a novel enveloped ribonucleic acid betacoronavirus and called 2019-nCov [3, 4]. The WHO designated the virus as severe acute respiratory syndrome coronavirus-2 (SARS-CoV-2) and the disease caused by the virus termed COVID-19 (the abbreviation of coronavirus disease 2019) in February 2020 [5]. Due to the rapid and global spread of the COVID-19, the WHO declared a pandemic indicating over 118,000 cases in over 110 countries around the world on March 11th, 2020 [6].

The contagiousness and infectious capability of the SARS-CoV-2 and reported mortality rates ranging from 2.3 to above $12 \%$ have threatened public health and raised concerns across the world $[2,7]$. The case-fatality rate was found to be higher among older patients with preexisting comorbidities including cardiovascular disease, diabetes, chronic respiratory disease, hypertension, and cancer [8]. Furthermore, among patients with severe symptoms of COVID-19, 58\% had hypertension, 25\% had heart disease, and $44 \%$ had arrhythmia [9].

Phylogenetic analyses and genomic sequencing revealed that SARS-CoV-2 is a betacoronavirus belonging to the family Coronaviridea closely related with the member of other human pathogenic betacoronaviruses: severe acute respiratory disease coronavirus (SARS-CoV) and Middle East respiratory syndrome coronavirus [4]. Cell entry mechanism of SARS-CoV-2, similar to the other pathogenic betacoronaviruses, depends on binding of the viral spike (S) protein to the human host cell membrane protein angiotensinconverting enzyme 2 (ACE2) and the serine protease TMPRSS2 for S protein priming expressed by particularly type II alveolar cells of the lung, heart, intestine, kidney, and blood vessels [10]. The SARS-CoV-2 uses ACE2 to infect target cells and the expression of the ACE2 levels are increased following treatment with angiotensin-converting enzyme inhibitors (ACEIs); in addition, angiotensin receptor blockers (ARBs) has emerged speculation that patients with COVID-19 receiving these drugs may be under at a potentially increased risk for developing severe and fatal illness $[11,12]$. Initial studies from China reports showing that essential hypertension could be a risk factor for the severity of disease and mortality in hospitalized COVID-19 patient which support the aforementioned hypotheses and have led some patients to stop taking ACEIs and ARBs [13]. The American and European cardiology societies, therefore, issued position statements which addressed concerns on using ACEIs and ARBs in COVID-19 and recommended continuation of these drugs for patients who were already treated for hypertension due to the lack of scientific or clinical data to support discontinuation [14, 15]. Consequently, whether ACEIs/ARBs medications or hypertension increase the severity of COVID-19 or not still remains to be unanswered due to the lack of evidence.

In the present study, we aimed to investigate the possible relationship between the use of ACEIs/ARBs for hypertension and inhospital clinical severity of SARS-CoV-2 infection and to identify the requirement for treatment in the intensive care unit (ICU), mechanical ventilation, and mortality rate.

\section{Methods}

This multicenter, observational, and retrospective study included a total of 247 adult Caucasian patients hospitalized with the diagnosis of COVID-19 from March 15th, 2020 to April 15th, 2020 as confirmed by real-time polymerase chain reaction from four hospitals in Istanbul. Inclusion criteria were as follows: age $\geq 18$ years, having COVID-19 associated respiratory tract infection (pneumonia), presence of dyspnea and/or decreased oxygen saturation. Patients under the age of 18 years old, missing medical data, having pregnancy, and patients with acute myocardial infarction were excluded. The patients' demographic information including age and sex, medical history, cigarette use, current medications, comorbidities such as hypertension, diabetes mellitus, coronary heart disease, congestive heart failure, chronic obstructive pulmonary disease or chronic renal disease, clinical characteristics such as fever, cough, fatigue, dyspnea or sore throat, laboratory parameters such as hemoglobin, platelet count, C-reactive protein (CRP), ferritin, D-dimer and creatinine, imaging study findings including chest X-ray or thoracic computed tomography (CT) were collected and analyzed in a common electronic medical system designed for all participant centers. Patients who were receiving antihypertensive therapy with the diagnosis of hypertension at the time of enrollment were accepted as hypertensives. In all patients, unilateral or bilateral lung lesions were present on thoracic CT images at the time of admission. All patients continued to receive their medication previously prescribed, including ACEIs and ARBs and no changes were made in their routine treatment regimens during the hospital stay.

Data including clinical outcomes were obtained from the electronic database system and confirmed by chest diseases and infectious diseases departments. The duration of hospitalization, clinical outcomes, and requirement for treatment in the ICU and mechanical ventilation were recorded. The primary outcome was defined as the need of therapy in the ICU, 
mechanical ventilation or occurrence of death. Tachypnea (respiratory rate $>30 / \mathrm{min}$ ), $\mathrm{SpO} 2<90 \%$ or $<70 \mathrm{mmHg}$ (in room air without response to nasal oxygen up to $12 \mathrm{~L} / \mathrm{min}$ with reservoir), progressive dyspnea and increased work of breathing, lactate level of $>2 \mathrm{mmol} / \mathrm{L}$, hypotension (systolic blood pressure $<90 \mathrm{mmHg},>40 \mathrm{mmHg}$ drops from initial blood pressure, mean arterial pressure $<65 \mathrm{mmHg}$ ), organ dysfunction (confusion, renal failure, liver dysfunction, and elevated troponin I) were accepted as criteria for therapy in ICU. A written informed consent was obtained from each patient. The study protocol was approved by the institutional Ethics Committee (220-05/44) and local Government Health Authority (2020-05-04T13_30_55). All participants gave informed consent and the study was conducted in accordance with the principles of the Declaration of Helsinki.

\section{Statistical analysis}

Statistical analysis was performed using the R-software v.3.5.1 (R statistical software, Institute for Statistics and Mathematics, Vienna, Austria) with "rms", "ggplot2" and "rstanarm" packages. Continuous variables were expressed in mean \pm standard deviation (SD), or median and interquartile range, while categorical variables were expressed in number and percentage. The primary outcome was defined as the composite of need for ICU, mechanical ventilation, or occurrence of death. Clinically and biologically plausible variables which were found to be associated with poor outcomes in recent COVID-19 studies were selected as candidate predictors $[8,9,11-13]$. Variables with a frequency of $<5 \%$ and $>95 \%$ or predictors having a high level $(>50 \%)$ of missing data were not included in the models. Before the modeling period, variables with missing values were predicted by multiple imputation. We built a baseline model (Model-1) from age, sex, D-dimer, neutrophil-tolymphocyte ratio (NLR) and CRP measurements. Then, we included the history of hypertension (Model-2) and the use of ACEIs and ARBs (Model-3) to Model-1, respectively. The primary outcome was present in 48 patients. There were five variables $(\mathrm{df}=5)$ in Model-1, and six variables in Model-2 and Model-3 ( $\mathrm{df}=6)$. We determined the outcome/df $=10$ for Model-1, and outcome/df $=8$ for Model- 2 and Model-3. To reduce the overfitting risk during the modeling period, we used penalized maximum likelihood logistic regression analysis to investigate the possible association between the primary outcome and candidate predictors. We established the relationship between the outcomes and variables with an adjusted odds ratio (OR) and $95 \%$ confidence interval (CI). Among variables included in the modeling process, log transformation of NLR, Ddimer, and CRP were used, since recent studies established the right skewness for these parameters [9, 13, 16, 17].
After the modeling, numerical variables which strongly correlated with the primary outcome were plotted using the restricted cubic spline transformation to obtain 2- and 3dimentional plots. The relative importance of each predictor in the models was estimated with partial chi-square $\left(\chi^{2}\right)$ value for each predictor divided by the model's total $\chi^{2}$, which estimates the independent contribution of the predictor to the variance of the outcome. The most effective way for quantification of added predictive values of new measurement is to assess changes in the model's performance. We used assessment of fit (likelihood ratio $\chi^{2}$ ), quality (Akaike and Bayesian information criteria-AIC and $\mathrm{BIC}$ ), and predictive accuracy (c-index) and $R^{2}$ as performance indices. Likelihood ratio $\chi^{2}$ values of the models were compared with the lrtest. Supportive analyses were performed using the Bayesian logistic regression. Both weakly informative and mildly skeptical informative prior distributions were used. The relationship between the outcome and the variable as adjusted by the Bayesian posterior median and $95 \%$ credible interval (CrI) was carried out. We used the Watanabe AIC, Loo information criteria (LOOIC or expected log predicted density-ELPD), and R2 to assess the performances of the models. A $p$ value of $<0.05$ was considered statistically significant.

\section{Results}

Of a total of 247 hospitalized COVID-19 patients, 154 were males and 93 were females with a mean age of $51.3 \pm 14.2$ (range, 18-89) years. Of all patients, 48 were treated in the ICU via either high flow oxygen/noninvasive mechanical ventilation $(n=12)$ or mechanical ventilation $(n=36)$. The median length of ICU stay was 13 (range, 7-18) days. Four of the intensive care patients died. Other patients were followed in the COVID-19 services. The median follow-up was 7 (range, 6-11) days. Baseline demographic and clinical characteristics of the patients are shown in Table 1.

The most common symptoms were fever, cough, and weakness. Dyspnea was present in $40.1 \%$ of the patients at the initial admission. Symptoms of the patients on admission are presented in Table 2. A total of $31.6 \%$ of COVID19 patients were recently diagnosed with hypertension and were on medical treatment. Our hypertensive patients $(n=$ 81) were receiving the following antihypertensives: ACEIs $(n=14,17.2 \%)$, ARBs $(n=35,43.2 \%)$, calcium channel blockers $(n=38,37.0 \%)$, beta blockers $(n=37,45.6 \%)$, diuretics $(n=22,27.1 \%)$, and alpha blockers $(n=8,9.8 \%)$ either as mono- or combination therapy. In our study all of the patients received hydroxychloroquine $200 \mathrm{mg}$ twice for 5 days according to Ministry of Health's guidelines. Favipiravir and lopinavir/ritonavir were only used in patients treated in the ICUs. 
Table 1 Baseline demographic and clinical characteristics of patients with COVID-19.

\begin{tabular}{|c|c|c|c|c|}
\hline & $n$ & $\begin{array}{l}\text { Group 1 } \\
(N=199)\end{array}$ & $\begin{array}{l}\text { Group 2 } \\
(N=48)\end{array}$ & $p$ value \\
\hline Age & 247 & $49.8 \pm 13.7$ & $56.5 \pm 14.8$ & $p=0.002$ \\
\hline Gender (female) \% ( $n)$ & 247 & $41 \%(81)$ & $25 \%(12)$ & $p=0.044$ \\
\hline Diabetes mellitus \% $(n)$ & 247 & $13 \%(25)$ & $15 \%(73)$ & $p=0.708$ \\
\hline Hypertension \% (n) & 247 & $28 \%(55)$ & $48 \%(23)$ & $p=0.007$ \\
\hline Coronary heart disease $\%(n)$ & 247 & $8 \%(16)$ & $15 \%(7)$ & $p=0.161$ \\
\hline Congestive heart failure $\%(n)$ & 247 & $0 \%(0)$ & $4 \%(2)$ & $p=0.004$ \\
\hline COPD \% $(n)$ & 247 & $5 \%(9)$ & $10 \%(5)$ & $p=0.113$ \\
\hline Chronic kidney disease $\%(n)$ & 247 & $3 \%(5)$ & $10 \%(5)$ & $p=0.013$ \\
\hline Obesity \% (n) & 247 & $9 \%(17)$ & $4 \%(2)$ & $p=0.307$ \\
\hline Cancer \% $(n)$ & 247 & $4 \%(8)$ & $4 \%(2)$ & $p=0.963$ \\
\hline ACEIs/ARBs $\%(n)$ & 247 & $18 \%(36)$ & $27 \%(13)$ & $p=0.161$ \\
\hline Calcium channel blockers $\%(n)$ & 247 & $14 \%(28)$ & $21 \%(10)$ & $p=0.244$ \\
\hline LMWH \% (n) & 247 & $25 \%(49)$ & $83 \%(40)$ & $p=0.001$ \\
\hline Hemoglobin $(\mathrm{g} / \mathrm{dL})$ & 175 & $12.70 / 13.60 / 14.80$ & $12.05 / 12.90 / 14.05$ & $p=0.012$ \\
\hline Platelet count $10^{3} / \mu \mathrm{L}$ & 242 & $159 / 198 / 239$ & $135 / 178 / 252$ & $p=0.242$ \\
\hline C-reactive protein $(\mathrm{mg} / \mathrm{dL})$ & 242 & $0.63 / 1.71 / 4.96$ & $4.36 / 8.86 / 14.50$ & $p=0.002$ \\
\hline Ferritin (ng/mL) & 206 & $86 / 234 / 490$ & $290 / 566 / 1037$ & $p<0.001$ \\
\hline D-dimer $(\mu \mathrm{g} / \mathrm{mL})$ & 217 & $0.265 / 0.429 / 0.725$ & $0.610 / 1.070 / 2.380$ & $p<0.001$ \\
\hline Creatinine (mg/dL) & 238 & $0.70 / 0.86 / 1.00$ & $0.80 / 0.99 / 1.15$ & $p=0.004$ \\
\hline NLR & 235 & $8.13 \pm 5.82$ & $3.18 \pm 2.33$ & $p<0.001$ \\
\hline
\end{tabular}

Group 1: patients treated in COVID-19 service; Group 2: patients treated in the intensive care unit. $A C E I / A R B$ angiotensin-converting enzyme inhibitor/angiotensin receptor blocker, $C O P D$ chronic obstructive pulmonary disease, $L M W H$ low molecular weight heparin, $N L R$ neutrophil-to-lymphocyte ratio.
We built a model including age, sex, baseline D-dimer, CRP, and NLR (Model-1). Then, we added hypertension to the model (Model-2), followed by the use of ACEIs and ARBs to the model (Model-3). In all models NLR and Ddimer levels had a strong association with the outcomes, indicating that these parameters could explain the majority of the variation in outcomes (Table 3 and Fig. 1). The partial effect plots of variables in Model-2 and Model-3 are shown in Fig. 2. Furthermore, the relationship between the outcomes and NLR and D-dimer levels, as the strongest predictors in our models, are shown in Fig. 3.

There was no significant correlation between the outcomes and use of ACEIs and ARBs (frequentist $\mathrm{OR}=0.82$, 95\% CI $0.29-2.34, p=0.715$ and Bayesian posterior median $\mathrm{OR}=0.80,95 \%$ CI $0.31-2.02$ ) in Model-2 and history of hypertension (frequentist $\mathrm{OR}=1.23,95 \% \mathrm{CI}$ $0.52-2.92, p=0.631$ and Bayesian posterior median $\mathrm{OR}=$ $1.25,95 \%$ CI $0.58-2.60$ ) in Model-3. Both hypertension and use of ACEIs/ARBs had a very low contribution to the variation of outcome. Furthermore, the inclusion of ACEIs/ ARBs use (Model-2) and hypertension (Model-3) to the models had no significant effect on model performances
Table 2 Symptoms of patients at the time of presentation $(n=247)$.

\begin{tabular}{lccc}
\hline & Group 1 & Group 2 & $p$ value \\
\hline Fever & $83.8 \%$ & $89.6 \%$ & 0.377 \\
Cough & $79.2 \%$ & $81.3 \%$ & 0.844 \\
Fatigue & $58.4 \%$ & $64.6 \%$ & 0.514 \\
Dyspnea & $31.5 \%$ & $72.9 \%$ & $<0.0005$ \\
Myalgia & $28.4 \%$ & $54.2 \%$ & 0.002 \\
Sore throat & $22.3 \%$ & $47.9 \%$ & 0.001 \\
Arthralgia & $10.7 \%$ & $33.3 \%$ & $<0.0005$ \\
Vomiting & $10.2 \%$ & $4.2 \%$ & 0.087 \\
Hypo or anosmia & $7.1 \%$ & $22.9 \%$ & 0.001 \\
Diarrhea & $6.6 \%$ & $2.1 \%$ & 0.316 \\
Nausea & $6.1 \%$ & $2.1 \%$ & 1.00 \\
Headache & $6.1 \%$ & $10.4 \%$ & 0.383 \\
Rhinitis & $3.6 \%$ & $8.3 \%$ & 0.232 \\
Syncope & $2.5 \%$ & $2.3 \%$ & 0.586 \\
Vertigo & $2.0 \%$ & $2.0 \%$ & 1.00 \\
\hline
\end{tabular}

Data are given in number and percentage, unless otherwise stated. Group 1: patients treated in COVID-19 service; Group 2: patients treated in the intensive care unit. 
Table 3 Adjusted OR and 95\% CIs for individual predictors included in models.

\begin{tabular}{|c|c|c|c|}
\hline & Model-1 & Model-2 & Model-3 \\
\hline Age (from 41 to 60 years) & $\begin{array}{l}\mathrm{OR}=1.15(0.68-1.95) \\
p=0.589\end{array}$ & $\begin{array}{l}\mathrm{OR}=1.22(0.66-2.24) \\
p=0.511\end{array}$ & $\begin{array}{l}\mathrm{OR}=1.09(0.61-1.94) \\
p=0.753\end{array}$ \\
\hline Sex (female) & $\begin{array}{l}\mathrm{OR}=0.76(0.31-1.85) \\
p=0.549\end{array}$ & $\begin{array}{l}\mathrm{OR}=0.77(0.32-1.88) \\
p=0.575\end{array}$ & $\begin{array}{l}\mathrm{OR}=0.76(0.31-1.85) \\
p=0.557\end{array}$ \\
\hline D-dimer (from 0.3 to $0.9 \mathrm{U}$ ) & $\begin{array}{l}\mathrm{OR}=2.34(1.47-3.71) \\
p=0.0003\end{array}$ & $\begin{array}{l}\mathrm{OR}=2.32(1.46-3.69) \\
p=0.0003\end{array}$ & $\begin{array}{l}\mathrm{OR}=2.33(1.47-3.70) \\
p=0.0003\end{array}$ \\
\hline CRP (from 0.8 to $7.4 \mathrm{mg} / \mathrm{dl}$ ) & $\begin{array}{l}\mathrm{OR}=3.08(1.38-6.89) \\
p=0.0061\end{array}$ & $\begin{array}{l}\mathrm{OR}=3.07(1.37-6.90) \\
p=0.0063\end{array}$ & $\begin{array}{l}\mathrm{OR}=3.11(1.39-6.97) \\
p=0.0058\end{array}$ \\
\hline NLR (from 1.8 to 5.0 ) & $\begin{array}{l}\mathrm{OR}=2.98(1.65-5.35) \\
p=0.0003\end{array}$ & $\begin{array}{l}\mathrm{OR}=3.02(1.67-5.46) \\
p=0.0003\end{array}$ & $\begin{array}{l}\mathrm{OR}=2.90(1.60-5.26) \\
p=0.0004\end{array}$ \\
\hline ACEIs/ARBs & - & $\begin{array}{l}\mathrm{OR}=0.82,(0.29-2.34) \\
p=0.715\end{array}$ & - \\
\hline Hypertension & - & - & $\begin{array}{l}\mathrm{OR}=1.23(0.52-2.92) \\
p=0.631\end{array}$ \\
\hline
\end{tabular}

$A C E I$ angiotensin-converting enzyme inhibitor, $A R B$ angiotensin receptor blocker, $C I$ confidence interval, $C R P$ C-reactive protein, $N L R$ neutrophilto-lymphocyte ratio, $O R$ odds ratio.

Model-1

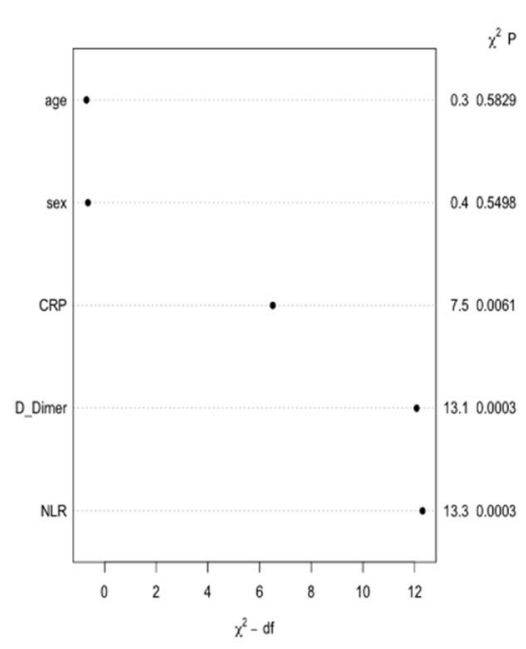

Model-2

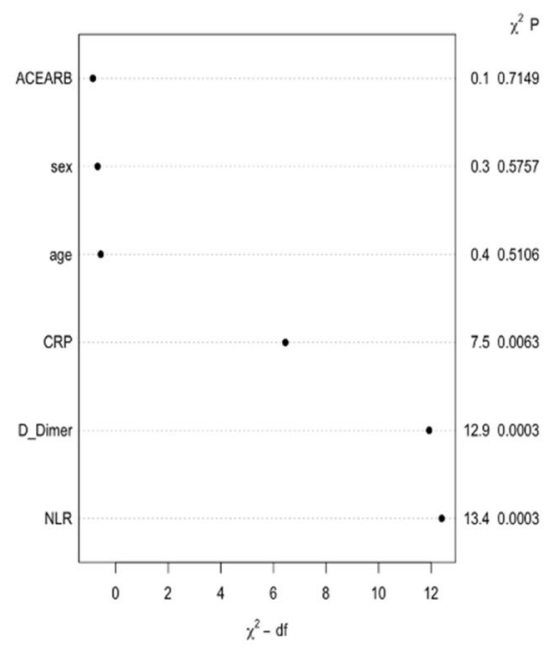

Model-3

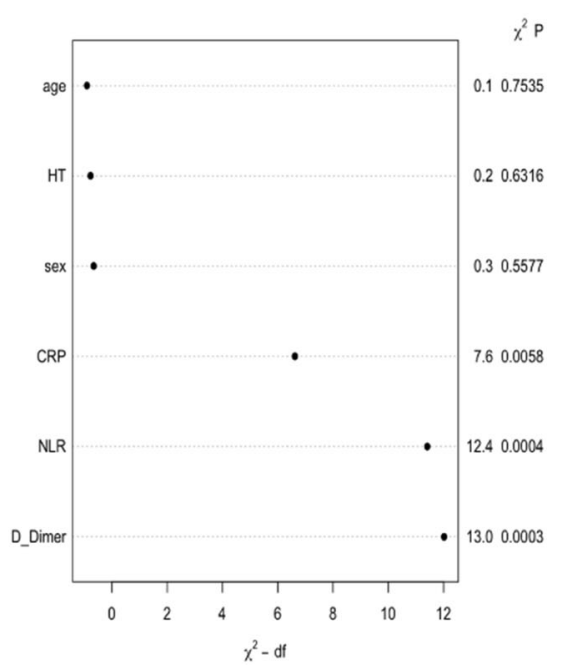

Fig. 1 Relative importance of predictors. In all models NLR, D-Dimer, and CRP levels evaluated by partial $\chi^{2}$ values indicated a strong correlation with outcomes. CRP C-reactive protein, NLR neutrophil-to-lymphocyte ratio.

(Table 4 and Fig. 4). The supportive Bayesian analyses found that the posterior probability of any $(\mathrm{OR}>1)$ harmful effect using ACEIs/ARBs of 0.34 and 0.40 with weakly and mildly skeptical informative priors (Fig. 5).

In our study thrombotic events were determined in three patients (two upper extremity venous thrombosis and one deep vein thrombosis). Two patients experienced minor bleeding (epistaxis and hemoptysis).

\section{Discussion}

In the present study, we investigated the possible relationship between worse clinical outcomes and the use of ACEIs/ARBs in hospitalized COVID-19 patients. Our study results showed no significant association between the presence of hypertension or using ACEIs/ARBs and primary outcomes in hospitalized COVID-19 patients. However, the plasma level of D-dimer and NLR were strongly correlated with the primary outcomes.

Earlier studies have demonstrated the presence of an association between advanced age, hypertension, and the severity of clinical setting and mortality in SARS-CoV-2 infection [9, 13, 16, 17]. However, it is well-documented that the prevalence of hypertension increases with age, and as a coexisting condition, it may adversely affect the clinical outcome and prognosis in viral and nonviral infections. Therefore, it is possible that the high prevalence of hypertension and treatment with ACEIs/ARBs reported in recent 
Model-2

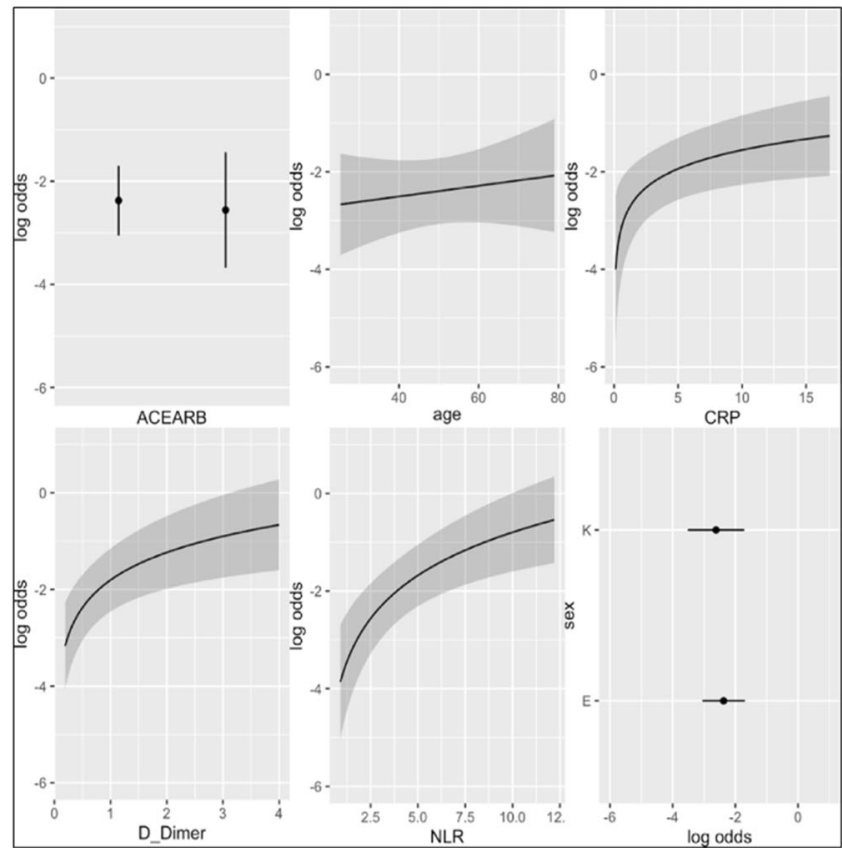

Model-3

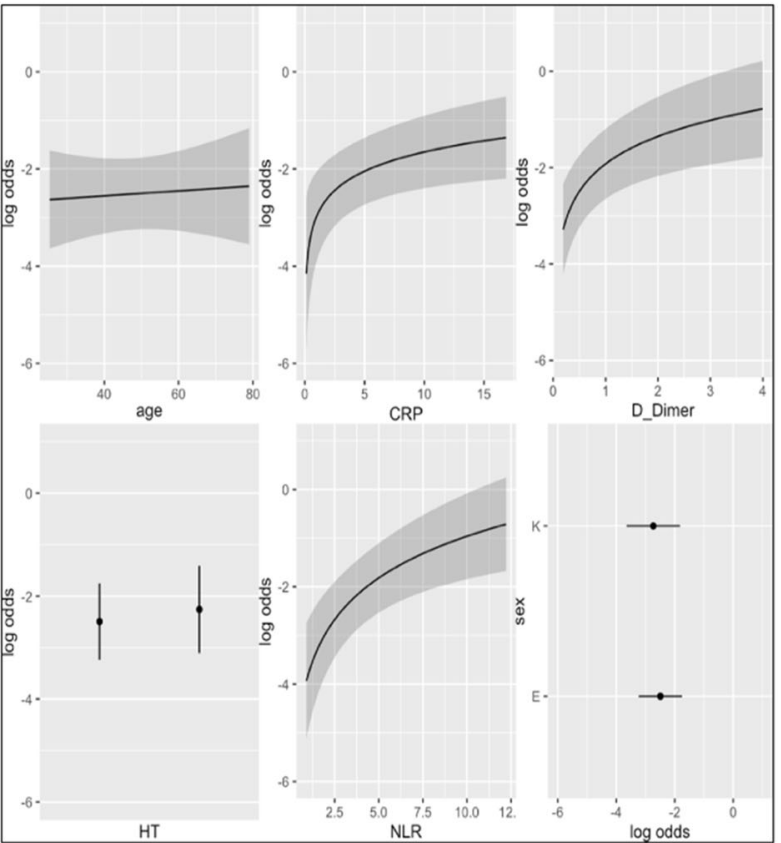

Fig. 2 Partial effect plots for Model-2 and Model-3. CRP C-reactive protein, NLR neutrophil-to-lymphocyte ratio, ACEI angiotensin-converting enzyme inhibitor, ARB angiotensin receptor blocker.

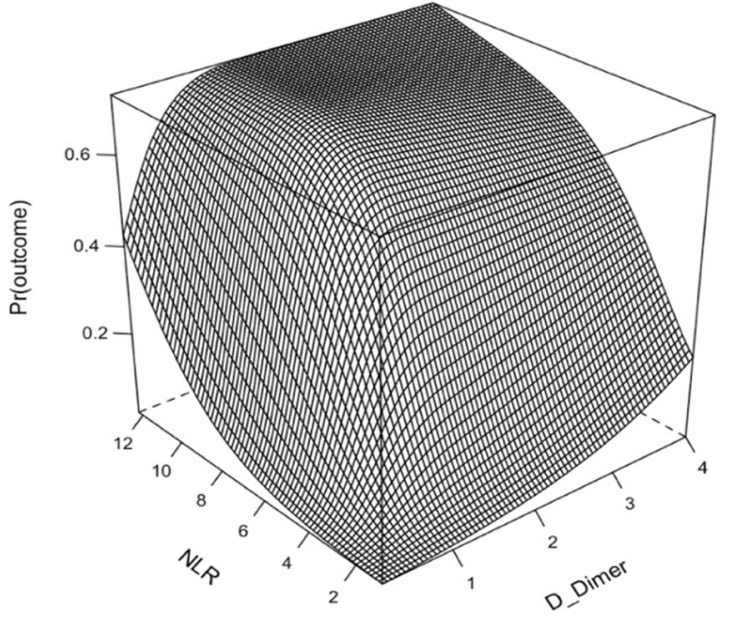

Fig. 3 3-dimentional plot for NLR, D-dimer level, and probability of outcome. NLR neutrophil-to-lymphocyte ratio. The relationship between the outcomes and NLR and D-dimer levels, as the strongest predictors in our models.

COVID-19 studies may be a potential confounder in risk prediction. The statistical models used in our study investigated all possibilities and role of each confounder on primary clinical outcomes separately and together with a variety of methods. Our analysis was unable to find a significant association between hypertension or the use of ACEIs/ARBs for its treatment and the clinical severity of COVID-19 defined as worsened primary outcomes (i.e., composite of need for ICU, mechanical ventilation or
Table 4 Comparisons of model performances.

\begin{tabular}{llll}
\hline & Model-1 & Model-2 & Model-3 \\
\hline Likelihood ratio $\chi^{2}$ & 83.7 & 83.9 & 83.9 \\
AIC & 173 & 174 & 174 \\
BIC & 193 & 198 & 198 \\
Frequentist $R^{2}$ & 0.451 & 0.452 & 0.452 \\
c-index & 0.887 & 0.888 & 0.886 \\
Brier score & 0.093 & 0.093 & 0.093 \\
Bayesian $R^{2}$ & 0.368 & 0.358 & 0.355 \\
WAIC & $164(21)$ & $167(21)$ & $167(21)$ \\
LOOIC (ELPD) & $0.0(0.0)$ & $-1.1(0.5)$ & $-1.3(0.5)$ \\
\hline$\chi^{2}$ chi-square, AIC & Akaite information criterion, BIC Bayesian \\
information criterion, & WAIC widely applicable information criterion, \\
LOOIC leave-one-out information criterion. &
\end{tabular}

death). Although the sample size of our study was relatively small and the patient population was younger than the recent COVID-19 studies.

Given the fact that the SARS-CoV-2 entered to the cells via ACE2 receptors reported in previous studies, it was hypothesized that drugs such as ACEIs/ARBs, which can influence the expression of ACE2 receptors, could increase susceptibility to viral invasion $[4,10,18,19]$, The role of ACE2, as an entry receptor for SARS-CoV-2 to cells was investigated in in vitro models and susceptibility to SARSCoV-2 infection was recently reported $[10,11,20]$. The 

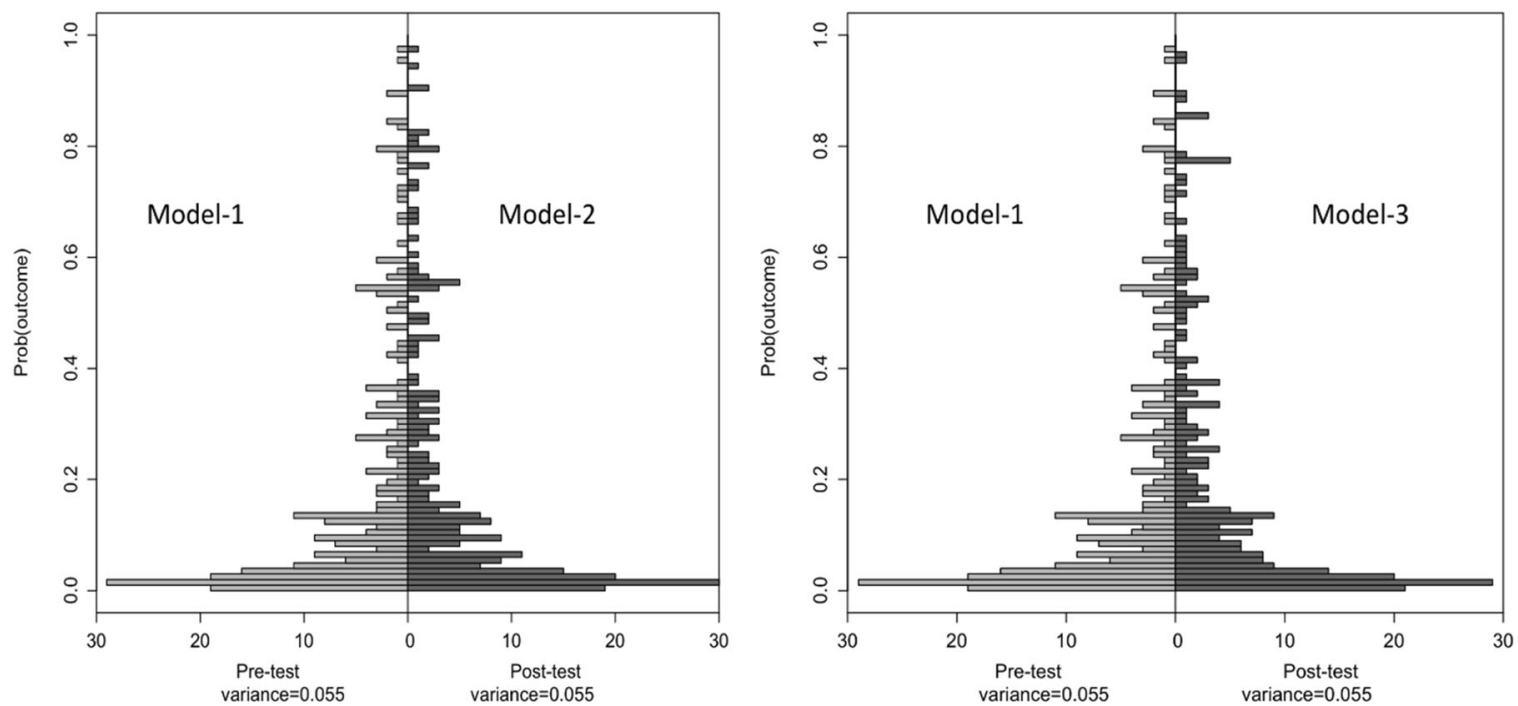

Fig. 4 A back-to-back histogram plot for distribution of probability of primary outcome in Models-1, 2, and 3. The inclusion of ACEIs/ ARBs use and hypertension to the models had no significant effect on model performances.

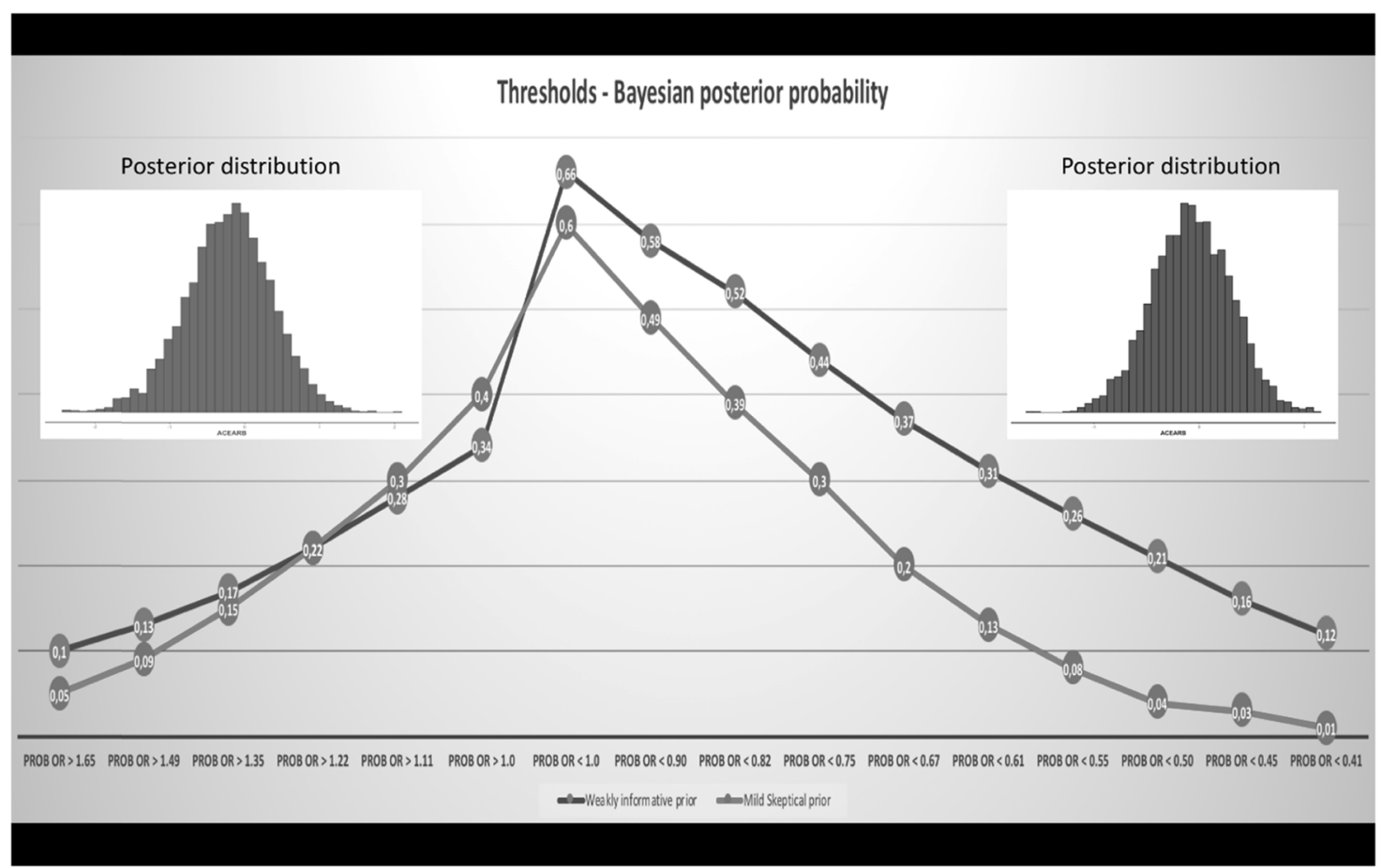

Fig. 5 Supportive Bayesian analyses. The supportive Bayesian analyses found that the posterior probability of any $(\mathrm{OR}>1)$ harmful effect using ACEIs/ARBs of 0.34 and 0.40 with weakly and mildly skeptical informative priors.

downregulation of ACE2 expression in the pathological process of lung injury and also levels of serum angiotensin II were reported to have positively correlations with viral load and lung injury in SARS-CoV-2 infection [19, 21, 22]. Therefore, the interaction between the SARS viruses and ACE2 has been proposed as a potential factor in their infectivity, i.e., an increased ACE2 expression may lead to a higher risk of SARS-CoV-2 infection [23, 24].
The ACEIs/ARBs have been shown to increase ACE2 expression and upregulation in animal and human studies [25-28]. Although there are limited and inconclusive human data, hypothetical concerns emerged whether these medications may increase the risk of infection and the severity of the disease and subsequent complications. Therefore, it was claimed that prescription of RAAS inhibitor drugs (i.e., ACEIs/ARBs) during the COVID-19 outbreak could be 
harmful, and even some proposals were offered about preferring other antihypertensive drug classes in these patients $[12,29]$. On the contrary, some researchers suggested that ACE2 had a role of counter-regulatory protective function for activation of the tissue RAAS and the upregulation of ACE2 might reduce the inflammation and also could protect the virus-related cell injury $[19,30]$. It was also demonstrated that recombinant ACE2 administration in mice protected from development of acute lung injury, suggesting that ACE2 mediates a cytoprotective role [31]. A clinical trial investigating the use of losartan in SARS-CoV-2 infected patients has been recently initiated [32].

In the literature, there are few clinical studies which evaluated the impact of RAAS inhibitors (i.e., ACEIs/ ARBs) on clinical outcomes in COVID-19 patients to guide clinicians in considering to discontinue or to maintain using these medications with conflicting results. A recent study suggested that there might be a protective role of ACEIs/ARBs on the mortality risk in patients with SARS-CoV-2 infection, while others showed no increased mortality risk with the use of ACEIs/ARBs [33-36]. Our study showed neither harmful nor beneficial relationship between the use of ACEIs/ARBs and inhospital clinical adverse outcomes.

Recently NLR at hospital admission was reported to be associated with inhospital mortality among patients with COVID-19 [37]. In the current study, we assessed the impact of commonly proposed prognostic factors on primary clinical outcomes in our models and determined that D-dimer and NLR were strong predictors of poor clinical outcomes (Tables 1, 2, 3 and Fig. 1).

In addition, CRP appeared to be significantly higher among patients experienced the primary clinical outcomes (Table 1); however, its effect on clinical outcome models was modest (Fig. 1).

D-dimer levels as marker of hypercoagulable state and intravascular thrombosis are frequently increased in clinical settings including severe infections, sepsis, deep vein thrombosis, and pulmonary embolism [38, 39]. Elevated levels of D-dimer and its association with poor clinical outcomes were reported in patients with COVID-19 in a recent study and a D-dimer level of $>2.0 \mu \mathrm{g} / \mathrm{mL}$ on admission (fourfold increase) effectively predicted inhospital mortality in patients with COVID-19 [40].

The CRP and NLR are the other common prognostic parameters examined in COVID-19 studies. Increased CRP levels are reported to be associated with the need of treatment in ICU, disseminated infection, and a higher mortality rate [41]. Lymphopenia as a cardinal finding in COVID-19 is frequently accompanied by elevated NLR [41]. Our study results revealed an increased NLR as the strong predictor of poor clinical outcomes. However, CRP had a modest effect on clinical outcomes based on our statistical models (Tables 1, 3 and Fig. 1).

Nonetheless, our study has some limitations. It has a retrospective and observational design with a relatively small sample size. We believe that further prospective, large-scale, long-term studies would yield more accurate results. However, the main strength of this study is that we were able to evaluate different scenarios using various statistical modeling and obtained consistent results. In addition, our results could not be generalized to all COVID-19 patients in general population because of sampling conditions based on hospitalized patients and this sampling bias may lead to artifactual association between presence of hypertension or use of ACEIs/ARBs and primary outcomes.

In conclusion, our study results showed that the presence of hypertension and use of ACEIs/ARBs were not significantly associated with poor primary clinical outcomes in COVID-19 patients. However, NLR and D-dimer levels were found to be strong predictors of clinical worsening. Our results did not confirm the concerns regarding the association between ACEIs/ARBs medication and an increased risk of short-term inhospital clinical severity of COVID-19. Our findings support recommendations to keeping on ACEIs/ARBs therapy in case of COVID-19 infection in patients who are already receiving these drugs.

\section{Summary table}

\section{What is already known about this topic}

- The SARS-CoV-2 uses ACE2 receptor to infect target cells.

- The expression of the ACE2 receptors are increased by treatment with ACE inhibitors ARBs.

- Essential hypertension can be a risk factor for the severity of disease and mortality in hospitalized COVID-19 patients.

\section{What does this article add}

- Intensive care therapy was required in $\sim 1 / 5$ of the patients with COVID-19.

- Hypertension was not associated with poor clinical outcomes in patients with COVID-19.

- ACEIs and ARBs did not increase the need for ICU, mechanical ventilation, or occurrence of death in COVID-19.

- Neutrophil-lymphocyte ratio and D-dimer levels were strong predictors of clinical worsening. 


\section{Compliance with ethical standards}

Conflict of interest The authors declare that they have no conflict of interest.

Publisher's note Springer Nature remains neutral with regard to jurisdictional claims in published maps and institutional affiliations.

\section{References}

1. Huang C, Wang Y, Li X, Ren L, Zhao J, Hu Y, et al. Clinical features of patients infected with 2019 novel coronavirus in Wuhan, China. Lancet. 2020;395:497-506.

2. Wu Z, McGoogan JM. Characteristics of and important lessons from the Coronavirus disease 2019 (COVID-19) outbreak in China. Summary of a report of 72314 cases from the Chinese centre for Disease Control and Prevention. JAMA. 2020;323:1239-42.

3. Zhu N, Zhang D, Wang W, Li X, Yang B, Song J, et al. China Novel Coronavirus Investigating and Research Team. A Novel Coronavirus from Patients with Pneumonia in China, 2019. N Engl J Med. 2020;382:727-33.

4. Lu R, Zhao X, Li J, Niu P, Yang B, Wu H, et al. Genomic characterization and epidemiology of 2019 novel coronavirus: implication for virus origins and receptor binding. Lancet. 2020;395:565-74.

5. World Health Organization. https://www.who.int/dg/speeches/ detail/who-director-general-s-remarks-at-the-media-briefing-on2019-ncov-on-11-february-2020. Accessed 12 Feb 2020.

6. WHO Director-General's opening remarks at the media briefing on COVID-19: 11 March 2020. https://www.who.int/dg/speeches/ detail/who-director-general-s-opening-remarks-at-the-mediabriefing-on-covid-19---11-march-2020. Accessed 30 Mar 2020.

7. Published by Statista Research Department. Coronavirus death rate in Italy as of April 9, 2020, by age group. 2020. https://www. statista.com/statistics/1106372/coronavirus-death-rate-by-agegroup-italy/. Accessed 9 Apr 2002.

8. Wu C, Chen X, Cai Y, Xia J, Zhou X, Xu S, et al. Risk factors associated with acute respiratory distress syndrome and death in patients with Coronavirus Disease 2019 pneumonia in Wuhan, China. JAMA Intern Med. 2020. https://doi.org/10.1001/jama internmed.2020.0994.

9. Wang D, Hu B, Hu C, Zhu F, Liu X, Zhang J, et al. Clinical characteristics of 138 hospitalized patients with 2019 novel Coronavirus-infected pneumonia in Wuhan, China. JAMA. 2020;323:1061-69. https://doi.org/10.1001/jama.2020.1585.

10. Hoffmann M, Kleine-Weber H, Schroeder S, Krüger N, Herrler T, Erichsen S, et al. SARS-CoV-2 cell entry depends on ACE2 and TMPRSS2 and is blocked by a clinically proven protease inhibitor. Cell. 2020;181:271-80.e8. https://doi.org/10.1016/j.cell. 2020.02.052.

11. Fang L, Karakiulakis G, Roth M. Are patients with hypertension and diabetes mellitus at increased risk for COVID-19 infection? Lancet Respir Med. 2020;8:e21.

12. Zheng YY, Ma YT, Zhang JY, Xie X. COVID-19 and the cardiovascular system. Nat Rev Cardiol. 2020;17:259-60. https://doi. org/10.1038/s41569-020-0360-5.

13. Guan WJ, Ni ZY, Hu Y, Liang WH, Ou CQ, He JX, et al. China medical treatment expert group for Covid-19. Clinical characteristics of Coronavirus disease 2019 in China. N Engl J Med. 2020;382:1708-20. https://doi.org/10.1056/NEJMoa2002032.

14. Bozkurt B, Kovacs R, Harrington B. HFSA/ACC/AHA statement addresses concerns Re: using RAAS antagonists in COVID-19. 2020. https://www.acc.org/latest-in-cardiology/articles/2020/03/17/ 08/59/hfsa-acc-aha-statement-addresses-concerns-re-using-raas-a ntagonists-in-covid-19.
15. de Simone G. Position statement of the ESC council on hypertension on ACE-inhibitors and angiotensin receptor blockers. 2020. https://www.escardio.org/Councils/Council-on-Hypertension-(CHT)/ News/position-statement-of-the-esc-council-on-hypertension-on-aceinhibitors-and-ang.

16. Chen N, Zhou M, Dong X, Qu J, Gong F, Han Y, et al. Epidemiological and clinical characteristics of 99 cases of 2019 novel coronavirus pneumonia in Wuhan, China: a descriptive study. Lancet. 2020;395:507-13.

17. Oren O, Kopecky SL, Gluckman TJ, Gersh JG, Blumenthal RS. Coronavirus disease 2019 (COVID-19): epidemiology, clinical spectrum and implications for the cardiovascular clinician. Expert analysis. 2020. https://www.acc.org/latest-in-cardiology/articles/ 2020/04/06/11/08/covid-19-epidemiology-clinical-spectrum-andimplications-for-the-cv-clinician.

18. Santos RAS, Sampaio WO, Alzamora AC, Motta-Santos D, Alenina N, Bader M, et al. The ACE2/angiotensin-(1-7)/MAS axis of the renin-angiotensin system: focus on angiotensin-(1-7). Physiol Rev. 2018;98:505-53.

19. Guo JUNYI, Huang ZHENG, Lin LI, MD, Jiagao LV. Coronavirus disease 2019 (COVID-19) and Cardiovascular disease: a viewpoint on the potential influence of angiotensin-converting enzyme inhibitors/Angiotensin receptor blockers onset and severity of severe acute respiratory syndrome coronavirus 2 infection. J Am Heart Assoc. 2020;9:e016219. https://doi.org/10. 1161/JAHA.120.016219.

20. Hofmann H, Geier M, Marzi A, Krumbiegel M, Peipp M, Fey $\mathrm{GH}$, et al. Susceptibility to SARS coronavirus $\mathrm{S}$ protein-driven infection correlates with expression of angiotensin converting enzyme 2 and infection can be blocked by soluble receptor. Biochem Biophys Res Commun. 2004;319:1216-21.

21. Kuba K, Imai Y, Rao S, Gao H, Guo F, Guan B, et al. A crucial role of angiotensin converting enzyme 2 (ACE2) in SARS coronavirus-induced lung injury. Nat Med. 2005;11:875-9.

22. Liu Y, Yang Y, Zhang C, Huang F, Wang F, Yuan J, et al. Clinical and biochemical indexes from 2019-nCoV infected patients linked to viral loads and lung injury. Sci China Life Sci. 2020;63:364-74.

23. Li W, Zhang C, Sui J, Kuhn JH, Moore MJ, Luo S, et al. Receptor and viral determinants of SARS-coronavirus adaptation to human ACE2. EMBO J. 2005;24:1634-43.

24. Wrapp D, Wang N, Corbett KS, Goldsmith JA, Hsieh CL, Abiona $\mathrm{O}$, et al. Cryo-EM structure of the 2019-nCoV spike in the prefusion conformation. Science. 2020;367:1260-3.

25. Ferrario CM, Jessup J, Chappell MC, Averill DB, Brosnihan KB, Tallant EA, et al. Effect of angiotensin-converting enzyme inhibition and angiotensin II receptor blockers on cardiac angiotensinconverting enzyme 2. Circulation. 2005;111:2605-10.

26. Ishiyama Y, Gallagher PE, Averill DB, Tallant EA, Brosnihan $\mathrm{KB}$, Ferrario CM. Upregulation of angiotensin-converting enzyme 2 after myocardial infarction by blockade of angiotensin II receptors. Hypertension. 2004;43:970-6.

27. Patel AB, Verma A. COVID-19 and angiotensin-converting enzyme inhibitors and angiotensin receptor blockers: What is the evidence? JAMA. 2020. https://doi.org/10.1001/jama.2020. 4812.

28. Vaduganathan M, Vardeny O, Michel T, McMurray JJV, Pfeffer MA, Solomon SD. Renin-angiotensin-aldosterone system inhibitors in patients with Covid-19. N Engl J Med. 2020. https://doi. org/10.1056/NEJMsr2005760.

29. Esler M, Esler D. Can angiotensin receptor-blocking drugs perhaps be harmful in the COVID-19 pandemic? J Hypertension. 2020;38:781-2.

30. Wang K, Gheblawi M, Oudit GY. Angiotensin converting enzyme 2: a double-edged sword. Circulation. 2020. https://doi.org/10. 1161/CIRCULATIONAHA.120.047049. 
31. Gu H, Xie Z, Li T, Zhang S, Lai C, Zhu P, et al. Angiotensinconverting enzyme 2 inhibits lung injury induced by respiratory syncytial virus. Sci Rep. 2016;6:19840.

32. Losartan for patients with COVID-19 requiring hospitalization. 2009. https://clinicaltrials.gov/ct2/show/NCT0431.

33. Zhang P, Zhu L, Cai J, Lei F, Qin JJ, Xie J, et al. Association of inpatient use of angiotensin converting enzyme inhibitors and angiotensin II receptor blockers with mortality among patients with hypertension hospitalized with COVID-19. Circ Res. 2020. https://doi.org/10.1161/CIRCRESAHA.120.317134.

34. Li J, Wang X, Chen J, Zhang H, Deng A. Association of reninangiotensin system inhibitors with severity or risk of death in patients with hypertension hospitalized for coronavirus disease 2019 (COVID-19) infection in Wuhan, China. JAMA Cardiol. 2020. https://doi.org/10.1001/jamacardio.2020.1624.

35. Mancia G, Rea F, Ludergnani M, Apolone G, Corrao G. Renin-angiotensine-aldosterone system blockers and the risk of Covid-19. N Engl J Med. 2020. https://doi.org/10.1056/NEJMoa 2006923.

36. Li J, Wang X, Chen J, Zhang H, Deng A. Association of renin-angiotensin system inhibitors with severity or risk of death in patients with hypertension hospitalized for Coronavirus disease 2019 (COVID-19) infection in Wuhan, China. JAMA Cardiol. 2020;e201624. https://doi.org/10.1001/jamacardio.2020.1624.

37. Yan X, Li F, Wang X, Yan J, Zhu F, Tang S, et al. Neutrophil to lymphocyte ratio as prognostic and predictive factor in patients with coronavirus disease 2019: a retrospective crosssectional study. J Med Virol. 2020:1-9. https://doi.org/10.1002/ jmv.26061.

38. Zhang L, Long Y, Xiao H, Yang J, Toulon P, Zhang Z. Use of Ddimer in oral anticoagulation therapy. Int $\mathrm{J}$ Lab Hematol. 2018;40:503-7. https://doi.org/10.1111/ijlh.12864.

39. Tang N, Li D, Wang X, Sun Z. Abnormal coagulation parameters are associated with poor prognosis in patients with novel coronavirus pneumonia. J Thromb Haemost. 2020;18:844-7.

40. Zhang L, Yan X, Fan Q, Liu H, Liu X, Liu Z, et al. D-dimer levels on admission to predict in-hospital mortality in patients with Covid19. J Thromb Haemost. 2020. https://doi.org/10.1111/jth.14859.

41. Terpos E, Ntanasis-Stathopoulos I, Elalamy I, Kastritis E, Sergentanis TN, Politou M, et al. Hematological findings and complications of COVID-19. Am J Hematol. 2020. https://doi.org/10. 1002/ajh.25829. 